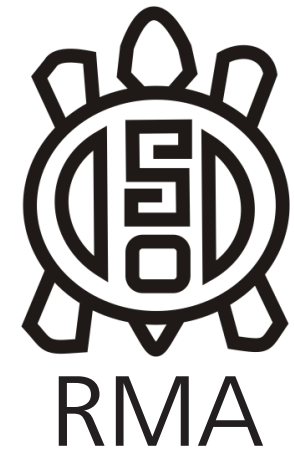

Dossier

\section{Aplicación de tecnologías 3D en sitios arqueológicos del valle de Ongamira, Córdoba, Argentina. Fotogrametría en excavaciones y morteros arqueológicos}

\author{
Application of 3D technologies in archaeological sites of Ongamira \\ valley, Córdoba, Argentina. Photogrammetry of archaeological \\ excavations and mortars
}

Bernarda Conte $y$ Andrés Robledo ${ }^{* *}$

\begin{abstract}
Resumen
Se presenta un aporte en la aplicación de nuevas tecnologías digitales dentro de los estudios arqueológicos. Para ello, a partir de tareas de relevamiento y prospección en el valle de Ongamira, se generaron modelos virtuales de morteros localizados en distintos lugares y sobre excavaciones estratigráficas en sitios al aire libre y aleros. Se utilizó la técnica de fotogrametría, con la cual se llevó a cabo el registro de 3 aleros rocosos con evidencias de ocupación, 8 pozos de excavaciones y 5 morteros, de los cuales 4 eran móviles y uno era en la roca base.

La aplicación de esta técnica requiere la toma de fotos de forma sistemática en diferentes ángulos. Luego de fotografiar la totalidad del objeto o el rasgo, se realizó un modelo digital empleando los programas VisualSFM y Meshlab. El resultado del uso de estos programas es un modelo virtual tridimensional en el cual nos permitía comprender la estructura del objeto original y sus características. Con el uso de estas herramientas esperamos contribuir al desarrollo de técnicas digitales para la revalorización, el registro, la conservación y difusión de lugares con evidencias de actividades humanas en el pasado.
\end{abstract}

Palabras clave: Arqueología 3D; Fotogrametría; Sierras Pampeanas Australes; Paisaje; Conservación.

\begin{abstract}
A contribution is presented for the application of new digital technologies within archaeological studies. In order to achieve this, virtual models were generated of mortars located in different places and on stratigraphic excavations in open air sites and rockshelters from surveying data collected in the Ongamira valley. Using the technique of photogrammetry, the record of 3 rock shelters with evidence of occupation was carried out, along with 8 excavation units and 5 mortars, of which 4 were mobile and one was in the base rock.

The application of this technique requires taking pictures systematically at different angles. After photographing the entire object or feature, a digital model was made using the VisualSFM and Meshlab programs. The result of this was a three-dimensional virtual model in which it allowed us to understand the structure of the original object and its characteristics. With the use of these tools we hope to contribute to the development of digital techniques for the revaluation, record, conservation and dissemination of places with evidence of human activities in the past.
\end{abstract}

Keywords: 3D Archaeology; Photogrammetry; Southern Pampeans Hills; Landscape; Conservation.

\section{Introducción}

El desarrollo de tecnologías tridimensionales como elementos de visualización y registro han experimentado un crecimiento en las últimas décadas. A partir de los avances tecnológicos en equipamientos y software, comenzó la aplicación de técnicas de digitalización dentro de diferentes disciplinas entre las cuales se encuentra la geografía, la topografía, la ingeniería, así como también el mundo patrimonial y la arqueología.

En estos campos, lo digital aparece como un nuevo elemento dentro de la antropología entendido como un vehiculizador de las relaciones sociales con el acento 
puesto en la tecnología y la cultura (Boellstorf 2012). La arqueología virtual (sensu López-Menchero Bendicho y Grande 2011:72) destaca en su utilidad para la gestión integral del patrimonio arqueológico. Así, puede pensarse en una práctica arqueológica mediada por lo digital permitiendo abarcar nuevas problemáticas en la conservación y la divulgación científica (Izeta y Cattáneo 2018).

El presente trabajo se encuentra enmarcado en un proyecto de arqueología en el valle de Ongamira, ubicado en la Sierra Chicas de la provincia de Córdoba. El mismo aborda el estudio de las sociedades que habitaron la región en diferentes contextos de ocupación datados hasta el momento entre ca. 950 años AP hasta ca. 6500 años AP en sitios al aire libre y aleros (Cattáneo et al. 2013 y 2019). Se confeccionaron modelos digitales desde dos líneas de evidencias: morteros identificados en distintos sectores del valle y excavaciones en aleros con evidencias de ocupaciones humanas. La propuesta de trabajo persigue dos objetivos complementarios. Por una parte, contribuir al desarrollo estrategias para el empleo de técnicas digitales en el relevamiento y posterior estudio de lugares con evidencias de actividades humanas. En segundo lugar, realizar un aporte a las técnicas de conservación y divulgación científica a partir del desarrollo de modelos digitales en tres dimensiones publicados en repositorios digitales de acceso abierto.

Sobre el uso de tecnologías digitales en la arqueología El uso de las tecnologías digitales en la arqueología, así como otras disciplinas de las ciencias humanas, busca la democratización de conocimientos utilizando estos medios como el canal conductor de la información. Nos brinda la posibilidad de crear, acceder y compartir una variedad de información a un público amplio de conocimientos (Richardson 2013).

La digitalización facilita la difusión cultural, ya que los modelos virtuales pueden ser entendidos como mecanismos de interpretación de los restos arqueológicos o producciones antropológicas (Gómez Roble y Quirosa García 2009). La aplicación de técnicas tridimensionales está funcionando como un medio de conservación del patrimonio arqueológico, así como también se aplica al registro y difusión de los datos (e.g. Izaguirre 2016; Charquero 2016). Mediante los modelos tridimensionales se busca replicar de manera fidedigna los modelos, de modo tal que los objetos digitales contengan los datos necesarios para llevar a cabo las interpretaciones, realizar análisis, entre otros. De este modo el material permite una mayor accesibilidad y por lo tanto mayor interactividad con otros agentes de conocimiento (Conte 2018).

Para llevar a cabo la digitalización de objetos mediante imágenes, es necesario tener en cuenta una diversidad de técnicas en la obtención de imágenes o archivos 2D y 3D. Las imágenes en 3D se logran mediante técnicas manuales o mecánicas a partir de mediciones directas y sistemáticas, como el sistema de luz estructurada, el escaneo laser y el modelado basado en imágenes. La fotogrametría corresponde a ésta última, basada en el relevamiento de imágenes donde se toman fotografías de un mismo objeto desde diferentes ángulos y a partir de allí se reconstruye de forma digital tridimensional (Ávido y Vitores 2015).

En base a la propuesta de este trabajo, la fotogrametría permite la medición digital de un objeto. Desde 1990 hasta la actualidad esta técnica avanzó junto con la tecnología desarrollando nuevas aplicaciones y casos de estudio. Permitiéndonos de este modo utilizar esta técnica como una herramienta para la conservación, preservación y divulgación científica de los elementos de investigación (Conte 2018).

La aplicación de tecnologías digitales tridimensionales incluye su aplicación en diversos campos de trabajos. En el caso de la arqueología, se visualiza en el desarrollo de programas de conservación del patrimonio (e.g. Tejado 2005; Charquero 2016; Izaguirre 2016; Iturbe et al. 2018); recreación de sitios arqueológicos de modo virtual (Greco 2016; Greco y Palamarczuk 2016). Así como el uso de los Sistemas de Información Geográfica, que permite visualizar modelos en tres dimensiones (Figuerero Torres e Izeta 2013; Lorenzo et al. 2019, entre otros). Por otra parte, su aplicación también se ha mostrado efectiva en la digitalización de elementos óseos de animales para muestras comparativas (Niven et al. 2009, entre otros) y también en estudios de morfometría en base a modelos 3D (eg. Van der Niet et al. 2010; Owen et al. 2014; entre otros).

En cuanto a los estudios realizados en el valle de Ongamira, se aplicó fotogrametría y reconstrucción tridimensional en dos ocasiones hasta el momento. En primer lugar, en el marco de la tesis de licenciatura de uno de los autores $(B C)$, se realizaron estudios morfométricos 3D sobre veintitrés falanges proximales de Lama glama y Lama guanicoe (Conte 2018; Conte e Izeta 2018). En una segunda oportunidad, se realizaron modelos 3D de dos especies de roedores histricognatos (Microcavia australis y Ctenomys aff. C. osvaldoreigi) procedentes del valle de Ongamira (Mignino et al. 2018). En ambos casos, además de generar una base de datos osteométrica virtual con posibilidades de seguir siendo utilizada a futuro, se otorgan herramientas para el análisis y la comparación de muestras zooarqueológicas procedentes de distintos contextos a los fines de aportar a la arqueología regional.

En el caso de este trabajo, en el marco de los estudios doctorales de uno de los autores (AR), se realizaron tareas de prospección, relevamiento y excavaciones de nuevos sitios arqueológicos en el valle de Ongamira (ver Tabla 1). Se identificaron aleros y espacios al aire libre con evidencias de ocupación humana en distintos momentos 
del Holoceno Medio y Tardío (Robledo 2016; Cattáneo e Izeta 2016).

Por ello, se presenta el relevamiento digital de la superficie de tres de los aleros registrados durante los trabajos de campo: Parque Natural Ongamira 1, Dos Lunas 2 y La Chacra de la Mula Negra 1. Así también, se realizaron relevamientos digitales de los perfiles obtenidos durante las excavaciones y sondeos de ocho sitios de alero y al aire libre (ver Tabla 1 para más detalle): Dos Lunas 2, Dos Lunas 3, Pozos Blancos, La Chacra de la Mula Negra 1, La Chacra de la Mula Negra 2, Molle de Piedra 1, Molle de Piedra 2 y Loma de la Cuesta.

Asociados a cursos de agua o bien a emplazamientos llanos del valle se identificaron hoyuelos o tacitas posiblemente utilizados para la molienda (ver Tabla 1). Los morteros se presentaban de dos tipos principales: A través de afloramientos de granito con una o varias oquedades, o posibles bases de molienda de vegetales o materias primas (Babot 2017); o bien, en bloques de granito o rocas de similar composición de dimensiones menores y con la posibilidad de ser transportados. En el caso de estos últimos, los relevados se encontraban fuera de su contexto original ya que los pobladores del lugar pudieron levantarlos y los llevaron cerca de sus hogares (ver Figura 1).

Sobre los morteros en particular, la arqueología los ha definido y estudiado de distintas maneras. En términos de Babot (2017), pueden ser considerados "aquellas manifestaciones arqueológicas correspondientes al sustrato geológico o grandes bloques excavados en formas redondeadas para generar una o más oquedades oblicuas o perpendiculares a la superficie de la roca" (Babot 2017:39). La ubicación de los morteros en un espacio determinado puede responder a formas particulares de constituir y habitar el paisaje en el pasado (Robledo et al. 2018).

\section{Materiales y métodos}

A partir de lo registrado durante las prospecciones, se llevaron a cabo los modelos 3D mediante la técnica de fotogrametría de tres aleros, ocho excavaciones, cuatro morteros móviles y una roca base con morteros (ver Tabla 1). Esta técnica consiste en disponer de

Figura 1. Morteros relevados en los contextos actuales. Mortero ubicado en la recepción de la estancia Dos Lunas.

Figure 1. Mortars registered in moder contexts. Mortar located at the entrance in Dos Lunas ranch. dos o más fotografías de un objeto tomadas desde diferentes perspectivas con el fin de obtener coordenadas tridimensionales de los puntos de un objeto (Conte 2018).

En nuestro caso se trabajó con una cámara DSLR Nikon D3300 con lente de $18-55 \mathrm{~mm}$ en modo manual. Esto permitió tener control total de los parámetros de exposición de imagen como la velocidad de obturación, la apertura del diafragma y la sensibilidad ISO (Conte 2018). Esto es un elemento importante ya que las fotografías fueron tomadas al aire libre y sin trípode, perdiendo el control total de la luz. Gracias al disparo en modo manual se pudo trabajar con mayor control en los modelos al aire libre.

Para tomar las fotos se buscó cubrir la mayor cantidad de caras expuestas del objeto mediante la secuencia de fotos que se tomaron en la distancia de un paso. Se hicieron la cantidad de pasos necesarios para dar toda la vuelta. Una vez completada esa vuelta se procedió a sacar fotos en dos ángulos más, repitiendo la secuencia de pasos.

Una vez obtenidas las fotografías se comenzó a trabajar con softwares que nos permitieron la creación de los modelos tridimensionales. Los programas Visual Structure from Motion System (VisualSFM) (Changchang Wu 2011) y Meshlab (Cignoni et al. 2008) se encuentran dentro de los softwares de código abierto con acceso, descarga y uso gratuito. Estos programas nos permiten generar la nube de puntos del objeto a partir de imágenes 2D (Figura 2), la cual luego será editada para la obtención de un objeto mallado (Figura 3), es decir un objeto que posea información sobre los colores y texturas, buscando representar de modo fidedigno el objeto físico (Figura 4) (Ávido y Vitores 2015; Conte 2018).

El resultado de todos estos programas es un modelo virtual tridimensional el cual se manipula por medio de la computadora. Debido al nivel de detalle y fidelidad de estos modelos podemos llegar a comprender la estructura

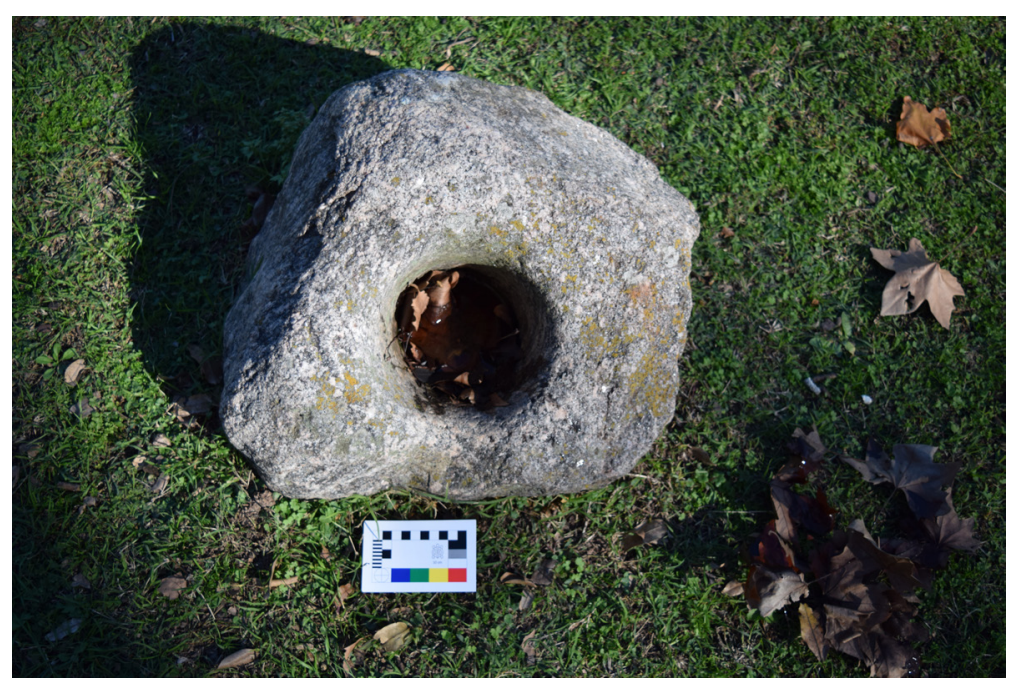

ISSN 1852-060X (impreso) / ISSN 1852-4826 (electrónico) 
Tabla 1. Colección virtual. Características propias del material 3D.

Table 1. Virtual collection. Characterstics of 3D material.

\begin{tabular}{|c|c|c|c|c|c|}
\hline & Sitio & $\begin{array}{l}N^{\circ} \text { de } \\
\text { fotos }\end{array}$ & $\begin{array}{l}\text { Número de } \\
\text { puntos }\end{array}$ & $\begin{array}{l}\text { Tamaño del } \\
\text { archivo }\end{array}$ & Link \\
\hline Alero & $\begin{array}{c}\text { Parque } \\
\text { Natural } \\
\text { Ongamira } 1 \\
\end{array}$ & 341 & $15,924,652$ & $230.266 \mathrm{~KB}$ & $\begin{array}{l}\text { http://suquia.ffyh.unc.edu.ar/handle/suquia/ } \\
3372\end{array}$ \\
\hline Alero & $\begin{array}{l}\text { La Chacra de } \\
\text { la Mula } \\
\text { Negra } 1\end{array}$ & 134 & $2,170,481$ & $273.849 \mathrm{~KB}$ & $\begin{array}{l}\text { http://suquia.ffyh.unc.edu.ar/handle/suquia/3 } \\
388\end{array}$ \\
\hline Alero & Dos Lunas 2 & 85 & $3,701,477$ & $163.163 \mathrm{~KB}$ & $\begin{array}{l}\text { http://suquia.ffyh.unc.edu.ar/handle/suquia/3 } \\
389\end{array}$ \\
\hline Excavación & $\begin{array}{l}\text { Loma de La } \\
\text { Cuesta }\end{array}$ & 110 & $7,492,678$ & 697.738 KB & $\begin{array}{l}\text { http://suquia.ffyh.unc.edu.ar/handle/suquia/3 } \\
391\end{array}$ \\
\hline Excavación & $\begin{array}{c}\text { La Chacra de } \\
\text { la Mula } \\
\text { Negra } 1 \mathrm{~A}\end{array}$ & 41 & $3,161,384$ & 429.679 KB & $\begin{array}{l}\text { http://suquia.ffyh.unc.edu.ar/handle/suquia/3 } \\
366\end{array}$ \\
\hline Excavación & $\begin{array}{c}\text { La Chacra de } \\
\text { la Mula } \\
\text { Negra } 2\end{array}$ & 36 & $2,130,162$ & $294.931 \mathrm{~KB}$ & $\begin{array}{l}\text { https://suquia.ffyh.unc.edu.ar/handle/suquia/ } \\
3365\end{array}$ \\
\hline Excavación & $\begin{array}{l}\text { Molle de } \\
\text { Piedra } 1\end{array}$ & 54 & 880.833 & $131.040 \mathrm{~KB}$ & $\begin{array}{l}\text { http://suquia.ffyh.unc.edu.ar/handle/suquia/3 } \\
370\end{array}$ \\
\hline Excavación & $\begin{array}{l}\text { Molle de } \\
\text { Piedra } 2\end{array}$ & 35 & 783.76 & $18.672 \mathrm{~KB}$ & $\begin{array}{l}\text { http://suquia.ffyh.unc.edu.ar/handle/suquia/3 } \\
371\end{array}$ \\
\hline Excavación & Dos Lunas 2 & 53 & $2,603,070$ & $334.970 \mathrm{~KB}$ & $\begin{array}{l}\text { http://suquia.ffyh.unc.edu.ar/handle/suquia/3 } \\
367\end{array}$ \\
\hline Excavación & Dos Lunas 3 & 32 & 743.115 & $108.648 \mathrm{~KB}$ & $\begin{array}{l}\text { http://suquia.ffyh.unc.edu.ar/handle/suquia/3 } \\
368\end{array}$ \\
\hline Excavación & Pozo Blanco & 19 & 617.664 & $77.472 \mathrm{~KB}$ & $\begin{array}{c}\text { http://suquia.ffyh.unc.edu.ar/handle/suquia/3 } \\
369 \\
\end{array}$ \\
\hline Morteros & Dos Lunas 5 & 56 & $5,913,917$ & $37.444 \mathrm{~KB}$ & $\begin{array}{c}\text { http://suquia.ffyh.unc.edu.ar/handle/suquia/3 } \\
385\end{array}$ \\
\hline Morteros & $\begin{array}{c}\text { Dos Lunas } 6 \\
\text { y } 7 \\
\end{array}$ & 55 & $3,624,480$ & $208.727 \mathrm{~KB}$ & $\begin{array}{l}\text { http://suquia.ffyh.unc.edu.ar/handle/suquia/3 } \\
387\end{array}$ \\
\hline Morteros & $\begin{array}{c}\text { Patio de la } \\
\text { Casa de } \\
\text { Roca } 1\end{array}$ & 184 & $1,825,122$ & $81.831 \mathrm{~KB}$ & $\begin{array}{l}\text { http://suquia.ffyh.unc.edu.ar/handle/suquia/3 } \\
383\end{array}$ \\
\hline Morteros & $\begin{array}{l}\text { Patio de la } \\
\text { Casa de } \\
\text { Roca } 2\end{array}$ & 79 & $9,699,804$ & $994.201 \mathrm{~KB}$ & $\begin{array}{l}\text { http://suquia.ffyh.unc.edu.ar/handle/suquia/3 } \\
390\end{array}$ \\
\hline
\end{tabular}

del objeto original y sus características, llegando a concretar interpretaciones y generando una nueva forma de intercambiar la información (Tejado 2005). Es así como con los resultados obtenidos, se cargaron los modelos digitales y todos los datos generados en el repositorio digital Suquía, perteneciente al Programa de Arqueología Digital de acceso libre y abierto (https://suquia.ffyh.unc. edu.ar/).

\section{Resultados}

Una vez analizadas todas las fotografías obtuvimos un total de tres aleros digitalizados, ocho sectores excavados de aleros y sitios al aire libre, cuatro morteros móviles y una roca base con morteros. En la tabla 1 se pueden observar la cantidad de puntos que contiene cada nube, el tamaño del mallado y el link donde se encuentran disponibles para su consulta.

Al respecto de los morteros, se digitalizaron cinco de los relevados en las investigaciones. Cuatro de estos eran individuales, ubicados en las cercanías a la casa principal de la Estancia Dos Lunas y en la entrada de la casa de la estancia Ongamira Turismo Rural. En el caso de este último, en el patio de su casa se encontraba la roca base con diez morteros dentro de su estructura.

En cuanto a los aleros relevados, previó a la digitalización se realizó un relevamiento general del terreno. De esta manera se caminó todo el alero capturando una foto por cada paso hasta cubrir toda la superficie. En el caso de Parque Natural Ongamira 1, fue reconstruido junto con la excavación arqueológica que se realizó entre los años 2015 y 2017 (ver Tabla 1). En el caso de Dos Lunas 2, se digitalizó el alero separado de la excavación, ya que esta fue realizada en las afueras del alero (ver Tabla 1). El tercer alero, La Chacra de la Mula Negra 1 se encuentra en el campo La Cuesta y se realizaron dos sondeos estratigráficos, también representados aparte (ver Tabla 1).

Por último, en el caso de las excavaciones realizadas, en cada caso variaron las estrategias implementadas por lo que puede observarse diferentes niveles de resolución 

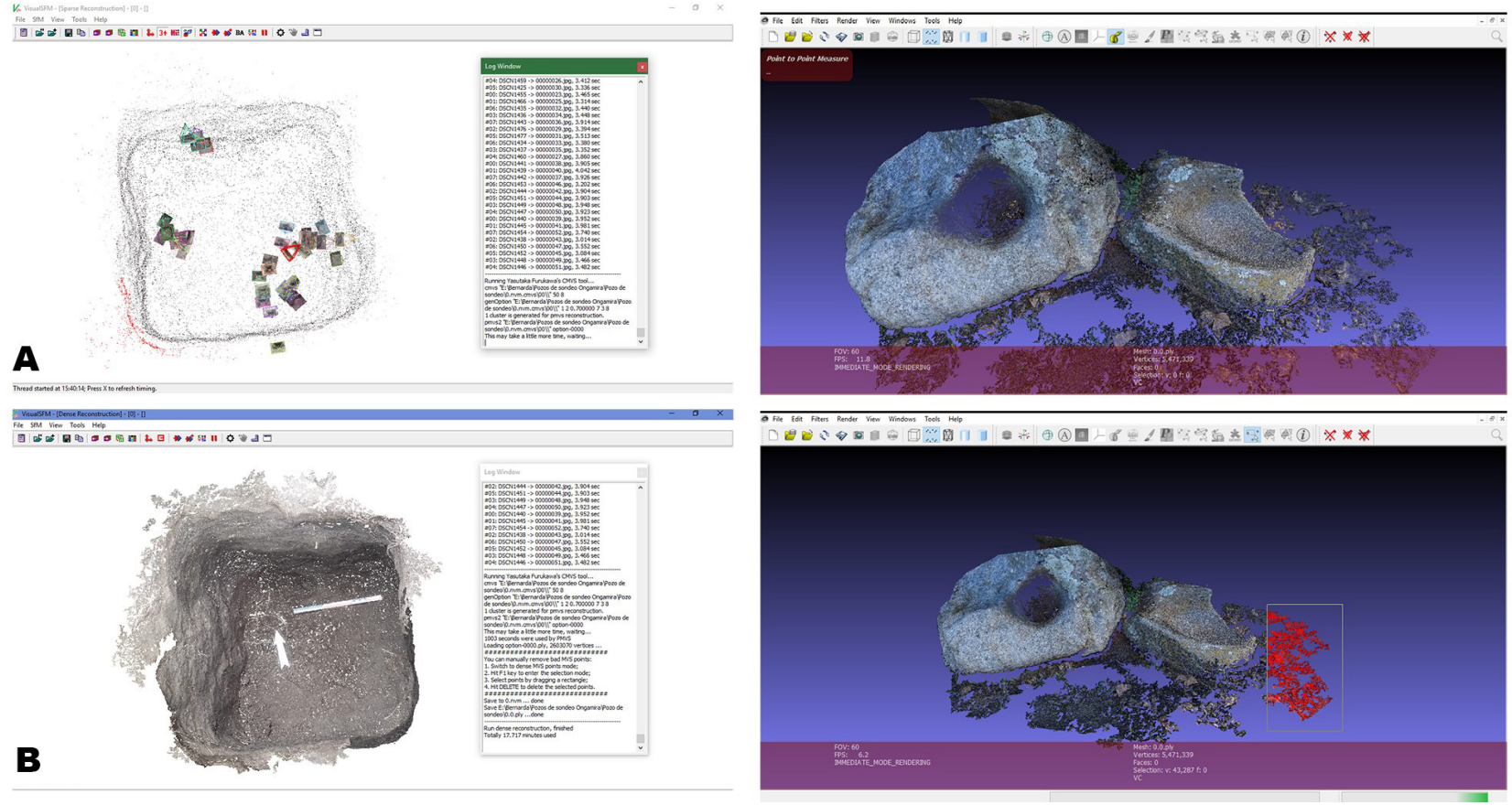

Figura 2. A) Nube de punto inicial generada por VisualSFM; B) Nube de puntos densa generada por VisualSFM

Figure 2. A) Initial point cloud by VisualSFM program; B) Dense point cloud by VisualSFM program.

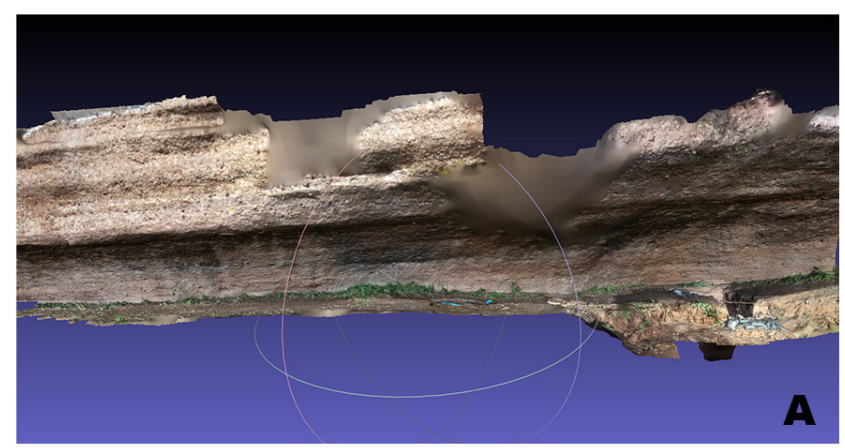

Figura 3. Edición de la nube de puntos en el programa MeshLab.

Figure 3. Edition of the point cloud in the MeshLab software
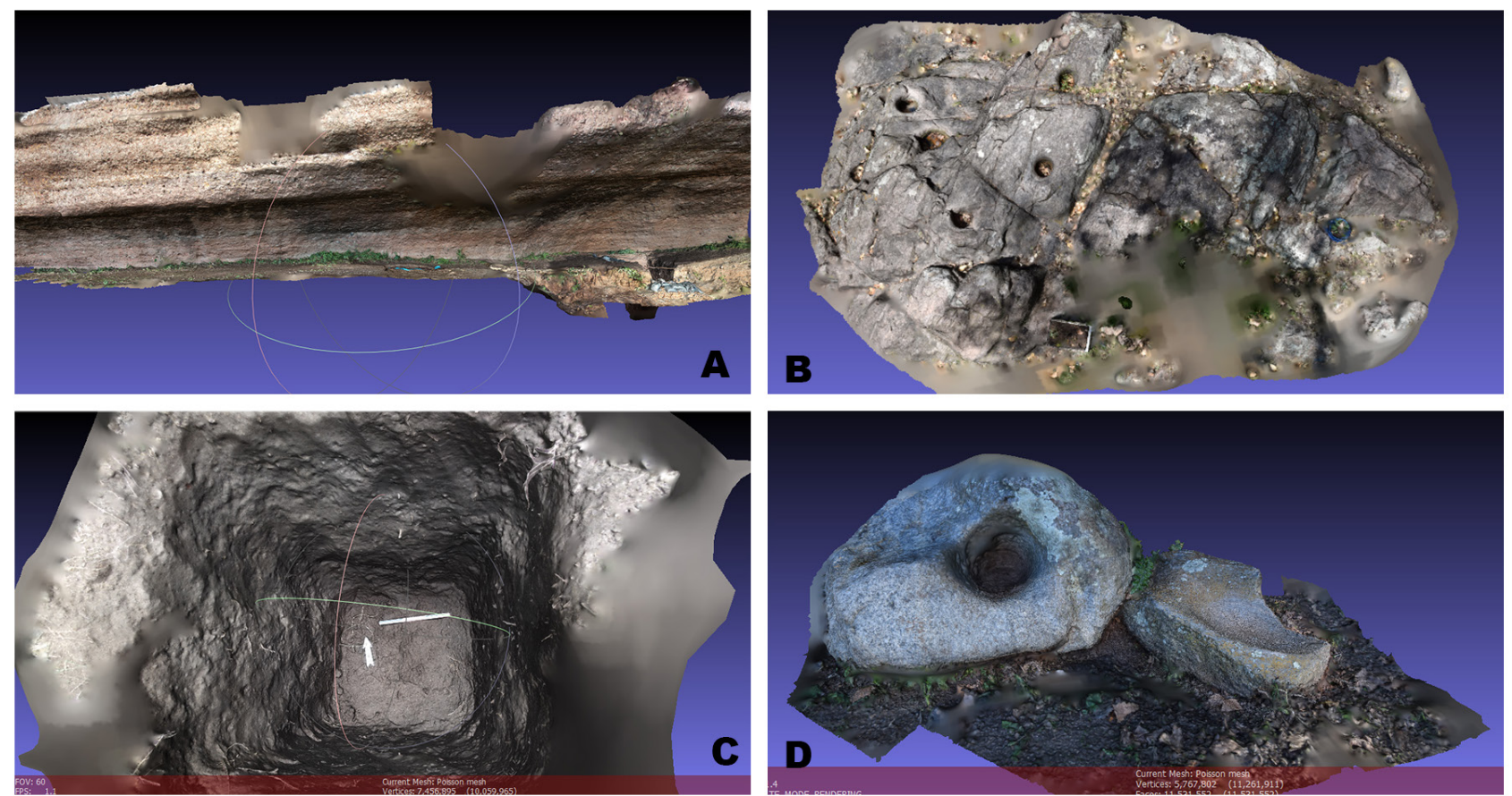

Figura 4. Objeto mallado en el programa MeshLab. A) El alero PNO1; B) Formación rocosa con morteros en su estructura. C) Excavación del sitio Dos Lunas 2. D) Morteros Dos Lunas 6 y 7.

Figure 4. Object mashed in the MeshLab program. A) The Alero PNO1; B) Rock formation with mortars in its structure; C) Site excavation Dos Luna 2; D) Mortars Dos Lunas 6 y 7. 
en algunos casos. En primera instancia se colocaron clips de colores para marcar las paredes hasta el fondo, un centímetro para delimitar la pared y además trabajamos con luz de una linterna. Con el fin de poder reconstruir el fondo del pozo, en sondeos posteriores se colocaron objetos refractantes como un Norte y Escala. Tal acción, sumada a que se aumentó la cantidad de fotos por sitio, permitió obtener mejores resultados permitiendo una reconstrucción de las excavaciones.

\section{Discusión y comentarios finales}

Consideramos que lo tecnológico (procesadores de texto, planillas de cálculos, modelos tridimensionales, imágenes, entre otros) resulta esencial dentro de la aplicación de metodologías de trabajo donde podemos plantear las dudas y poner a prueba los resultados mediante diferentes programas (Zubrow 2006). La aplicación de técnicas de digitalización es de gran utilidad en el desarrollo de la arqueología. Nos permite conservar rasgos de diferentes tipos de registro e instancias puntuales dentro de la tarea del arqueólogo como son las excavaciones. Pero también, nos brindan herramientas versátiles en la revalorización, registro, conservación y difusión de resultados (Conte 2018). Ya que aportan una mayor agilidad y facilidad en la divulgación del patrimonio, dentro y fuera del ámbito académico (Carosio et al. 2013; Vázquez y Díaz Pais 2014).

Trabajar con distintos tipos de registros como en el caso de este trabajo nos permitió realizar un aporte desde dos miradas. Por un lado, contribuir al estudio de las formas de vida de los grupos humanos que habitaron el valle en el pasado a partir de la digitalización de distintas materialidades, lugares, objetos, entre otros. Esto permite incorporar el registro arqueológico a un formato capaz de ser analizado por herramientas digitales útiles para la cuantificación y el análisis con softwares específicos que brinden nueva información y colabore en las interpretaciones que se realizan sobre los grupos humanos.

Por otro lado, se busca promover el uso de tecnologías tridimensionales con el fin de utilizarlas como un medio de divulgación científica sobre las distintas problemáticas dentro de la arqueología, como así también, entendiendo a estas tecnologías como una herramienta para la conservación del patrimonio. En ese sentido, las tecnologías avanzan y nos permiten tener herramientas para generar estudios interdisciplinares que impliquen el análisis de los objetos desde diferentes perspectivas.

La arqueología digital nos brinda elementos que nos permite interactuar con colegas y público en general de diferentes maneras. Así como explorar la relación de los elementos con otros investigadores y el público interesado, permitiéndonos observar su uso en investigaciones científicas y su relación con lo real (Boellstorff 2014). Un ejemplo de ello es el Programa de Arqueología Digital
(PAD) en el que se trabaja del material digitalizado, como por ejemplo una réplica tridimensional del objeto original (https://suquia.ffyh.unc.edu.ar/handle/suquia/2893), para el acceso libre y gratuito de un público diverso.

Córdoba, 3 de abril 2019

\section{Agradecimientos}

El presente trabajo se enmarca en el proyecto "Aproximaciones interdisciplinarias para el estudio arqueológico de sociedades cazadoras recolectoras, Córdoba, Argentina" dirigido por la Dra. Roxana Cattáneo y el Dr. Andrés Izeta. Queremos agradecerles a ellos y a los miembros del equipo por sus aportes y acompañamiento en las tareas realizadas en el campo. Así como también a los pobladores del valle quienes nos apoyan en nuestro trabajo desde hace años. Finalmente, queremos agradecer las sugerencias de los evaluadores que ayudaron a mejorar el trabajo; así como también a la comisión organizadora y participantes del 1er Congreso Argentino de Estudios Líticos en Argentina.

\section{Bibliografía}

Ávido, D., \& Vitores, M. (2015) Archivo fotográfico para la reconstrucción tridimensional. Arqueometría Argentina. Metodologías científicas aplicadas a bienes culturales. Datación, caracterización, prospección y conservación. Compiladores Pifferetti Andrián y Dosztal Irene. Editorial Aspha pp.: 223-232.

Babot, P. (2017) Morteros de Argentina: miradas desde y hacia la arqueología de los siglos XIX y XX y prospectos para futuros estudios. En "Actualizaciones en el estudio de piedras tacitas: nuevas perspectivas" editores: Carolina Belmar, Lino Contreras y Omar Reyes. Publicaciones de la Sociedad Chilena de Arqueología; Publicación del Centro de Estudios Humanos y Patrimoniales - Arqueólogos: 39-65

Boellstorff, T., (2012) Rethinking Digital Anthropology en: Digital Anthropology, Editado por Heather A. Horst y Daniel Miller. Oxford: Berg Publishers.

Carosio, S., Aguilar, J.P. \& Bárcena, J.R. (2013) Reconstrucción 3D y cálculo volumétrico de recipientes cerámicos. Alcances y limitaciones para el estudio y conservación cerámica de la Tamberia de Guandacol (Provincia de La Rioja). La Zaranda de Ideas. Revista de Jóvenes Investigadores en Arqueología 9(2): 57-76. Buenos Aires.

Cattáneo R., A. Izeta, A. Robledo, M. Takigami, M. Yoneda \& F. Tokanai, (2019). Nuevos datos cronológicos para el valle de Ongamira, Córdoba, Argentina: Implicancias teóricas sobre los modelos de ocupación humana durante el Holoceno. Acta de resúmenes de la XIII Jornadas de investigadores en arqueología y etnohistoria del Centro- 
Oeste del país, Río Cuarto, Córdoba.

Cattáneo G.R.; A.D. Izeta \& M. Takigami. (2013). Primeros fechados radiocarbónicos para el Sector B del sitio Alero Deodoro Roca (Ongamira, Córdoba, Argentina). Relaciones de la Sociedad Argentina de Antropología 38 (2): 1-9.

Cattáneo, G. R. \& A. D. Izeta, (Eds). 2016. Arqueología en el Valle de Ongamira. Córdoba, Universidad Nacional de Córdoba.

Changchang Wu (2011) "VisualSFM: A Visual Structure from Motion System", http://ccwu.me/vsfm/

Charquero Ballester A.M. (2016) Práctica y uso de la fotogrametría digital en arqueología. Revista Dama 1 pp: 139-157.

Cignoni, P., Callieri M., Corsini M., Dellepiane M., Ganovelli F. \& Ranzuglia G. (2008) MeshLab: an OpenSource Mesh Processing Tool. Sixth Eurographics Italian Chapter Conference, pp 129-136.

Conte, B. (2018). Reconstrucciones 3D aplicadas a la zooarqueología. El uso de morfometría $3 D$ en primeras falanges de camélidos arqueológicos del sitio Alero Deodoro Roca (Ongamira, Córdoba, Argentina). Tesis de licenciatura inédita, Facultad de Filosofía y Humanidades, Universidad Nacional de Córdoba.

Conte, B., \& Izeta, A. D. (2018). Métodos 3D aplicados en la arqueología. En: Congreso Nacional de Arqueometría, (pp. 422-426). San Miguel de Tucumán y Amaicha del Valle, Argentina.

Figuerero Torres, M.J. \& Izeta A.D. (2013) El uso de Sistemas de Información Geográfica (SIG) en Arqueología Sudamericana: una introducción. En: El uso de Sistemas de Información Geográficos en arqueología sudamericana. Figuerero Torres, M.J. y A. D. Izeta (Ed.) 5-8.

Gómez Roble, L. \& Quirosa García, M.V. (2009) Las nuevas tecnologías para definir el Patrimonio Cultural: Las reconstrucciones virtuales en España. Erph 4. Revista Digital, http://www.revistadepatrimonio.es/ descarga.php?nombre_documento=revistas/numero4/ estudiosgenerales/estudios/_pdf/estudiosgeneralesestudios.pdf accesado mayo 06, 2014.

Greco, C. (2016) Reconstrucción 3D de la excavación de Loma Redonda, Tilcara. https://sketchfab.com/ models/0363d5cafe5a4d2e9ebe7f3570cf94d8

Greco, C. \& Palamarczuk, V. (2016) Reconstrucción 3D de la excavación del sitio El Colorado. https://sketchfab.com/ models/cdf9e95d2e3040038de049c567ec2d19
Iturbe, A., Cachero, R., Cañal, D., \& Martos, A. (2018). Virtual digitization of caves with parietal Paleolithic art from Bizkaia. Scientific analysis and dissemination through new visualization techniques. Virtual Archaeology Review, 9(18), 57-65. https://doi.org/10.4995/var.2018.7579

Izaguirre, J.I. (2016) Nuevas Viejas Tecnologías. Modelos Tridimensionales aplicados a el Noroeste Argentinos. Tesis de Licenciatura publicado en la web http:// antropologia.filo.uba.ar/sites/antropologia.filo.uba.ar/ files/documentos/TESIS\%20IZAGUIRRE\%20final-.pdf.

Izaguirre, J.I. (2016) Nuevas Viejas Tecnologías. Modelos Tridimensionales aplicados a el Noroeste Argentinos. Tesis de Licenciatura publicado en la web http:// antropologia.filo.uba.ar/sites/antropologia.filo.uba.ar/ files/documentos/TESIS\%20IZAGUIRRE\%20final-.pdf.

Izeta, A. D., G. R. Cattáneo, A. I. Robledo \& J. Mignino. (2017). Aproximación multiproxy a los estudios paleoambientales de la provincia de Córdoba: El valle de Ongamira como caso. Dossier de las VI Jornadas Arqueológicas Cuyanas. Pág. 37.

Izeta, A.D. \& Cattáneo, R. (2018) ¿Es posible una arqueología digital en Argentina? Un acercamiento desde la práctica. Humanidades Digitales: Construcciones locales en contextos globales. Asociación Argentina de Humanidades Digitales, Buenos Aires.

López-Menchero Bendicho, V. M. \& Grande A. (2011) Hacia una Carta Internacional de Arqueología Virtual. Virtual Archaeology Review Vol. 2 N 4: 71-75 ISSN-e 1989-9947

Lorenzo, G., Lopéz, L., Moralejo R. A. \& del Papa L. M. (2019) Fotogrametría sfm aplicada a la determinación taxonómica de restos arqueofaunísticos. Virtual Archaeology Review, 10 (20): 70-83. https://doi. org/10.4995/var.2019.11094

Mignino, J., Izeta, A., Conte, B. \& Herrera, B. (2018). $3 \mathrm{D}$ photogrammetric models based on Hystricognath rodents. Upper Ongamira valley, northern Córdoba province, central Argentina. In: 13th International Conference of Archaeozoology, 3-7 de septiembre de 2018, Ankara, Turquía.

Niven, L., T. E. Steele, H. Finke, T. Gernat \& J.J. Hublin. (2009) Virtual skeletons: using a structured light scanner to create a 3D faunal comparative collection. Journal of Archaeological Science 39 (2009) 2018-2023.

Owen, J., K. Dobney, A. Evin, T. Cucchi, G. Larson \& U.S. Vidarsdottir. (2014) The zooarchaeological application of quantifying cranial shape differences in wild boar and domestic pigs (Sus scrofa) using 3D geometric 
morphometrics. Journal of Archaeological Science 43 (2014) 159 a 167. http://dx.doi.org/10.1016/j. jas.2013.12.010

Richardson, L. (2013) A Digital Public Archaeology? Papers from the Institute of Archaeology, 23(1): 10, pp. 1-12, DOI: http://dx.doi.org/10.5334/pia.431

Robledo A. (2016). Estudios arqueológicos de aleros y paisajes en el Parque Natural Ongamira (Depto. Ischilín, Córdoba). En Cattáneo, R. y A. Izeta (eds) Arqueología en el Valle de Ongamira, Córdoba (2010- 2015): 201-234. IDACOR-Museo de Antropología, Universidad Nacional de Córdoba.

Tejado, S. (2005) Escaneado en 3D y prototipado de las piezas arqueológicas: las nuevas tecnologías en el registro, conservación y difusión del patrimonio arqueológico. Iberia 8: 135-158.

Van der Niet, T., C. P. E. Zollikofer, M. S. Ponce de León, S. D. Johnson \& H. P. Linder. (2010) Three-dimensional geometric morphometrics for studying floral shape variation. Trends in Plant Science, 15(8):423-426. Postprint available at: http://www.zora.uzh.ch

Vazquez F. \& Díaz Pais E. (2014) Arqueología virtual en una estancia colonial argentina Virtual Archaeology Review Volumen 5 Número 10. ISSN: 1989-9947

Zubrow, E. (2006) Digital archaeology: The historical context. In T. L. Evans \& P. Daly (Eds.), Digital Archaeology: Bridging Method and Theory (pp. 10-31). London: Routledge. 